\title{
N-Word Licensing
}

https://doi.org/10.33806/ijaes.19.1.7

Naima Omari

Ibn Zohr University, Morocco

\begin{abstract}
The paper, conducted within the framework of the Minimalist Program (Chomsky1995), considers aspects of the licensing relation which obtains between Negation (Neg) and $N$-words in Amazigh. By N-words, I mean elements like ' $\hbar t t a+N P$ ' (no-one), which are licensed by Neg. The paper shows that the Neg-N-word relation in this language is one of feature checking, with Neg-features present on the $N$-word requiring to be paired with corresponding features on the functional head Neg prior to Spell-Out in the position they occupy, i.e. base generated in the c-command domain of Neg. It provides further evidence for the analysis of $N$-words from Moroccan Arabic, one which argues for a different view of feature checking/licensing from that proposed in Chomsky 1995.
\end{abstract}

Keywords: Amazigh, c-command, formal licensing, Minimalist Program, Moroccan Arabic, $\mathrm{N}$-words

\section{Introduction}

The paper, conducted within the framework of the Minimalist Program (Chomsky 1995), considers aspects of the licensing relation which obtains between Negation (Neg) and N-words. The discussions are based on data from Amazigh, in particular the Tashelhit variety spoken in the southwest of Morocco. By N-words, I mean elements like ' $\hbar t t a+N P '(n o ~ o n e)$ which are licensed by Neg1. I will argue that the Neg-N-word relation is one of feature checking, with Neg-features present on the $\mathrm{N}$-word requiring to be paired with corresponding features on the functional head $\mathrm{Neg}$ in a c-command configuration. I will also show such evidence in Amazigh can also be found in Moroccan Arabic (MA).

The paper is structured as follows. Section 1 presents the syntactic distribution of $\mathrm{N}$-words in Amazigh. Section 2 examines configurations that permit $\mathrm{N}$-word licensing and the level (or levels) of representation where licensing must take place. In the suggested analysis, it is shown that Spec-head agreement is not involved in $\mathrm{N}$-word licensing. On the basis of some evidence from Amazigh, it is suggested that the relevant configuration involves ccommand. The N-words are licensed in the c-command domain of $\mathrm{Neg}$ in the overt syntax. Section 3 provides further evidence for the analysis of $\mathrm{N}$-words from Moroccan Arabic (MA), one which argues for a different view of feature licensing from that proposed in Chomsky 1995.

\section{The basic distribution of $\mathbf{N}$-words}

The object of this section is to give an overview of the syntactic distribution of $\mathrm{N}$ words in Amazigh, and also to highlight some of the issues that will be addressed in subsequent sections. 
$\mathrm{N}$-words in Amazigh must co-occur with Neg in simple verbal sentences, as shown in (1):

$$
\begin{aligned}
& \text { (*ur) zri } \quad-\hbar \quad \text { htta-yan. } \\
& \text { Neg see+Perf+Neg -I not even -one } \\
& \text { "I did not see anyone." }
\end{aligned}
$$

Concerning the N-word ' $\hbar t t a+N P$ ', it displays the same distribution as any other argument NP. It can appear in object position (1), in subject position (2), or as the complement of a noun (3) or of a preposition (4):

$$
\begin{array}{ll}
\text { ur } \quad \text { i-mmuddi } & \text { htta-yan. } \\
\text { Neg he-travel+Perf+Neg } & \text { not-even-one } \\
\text { "Noone traveled." } &
\end{array}
$$

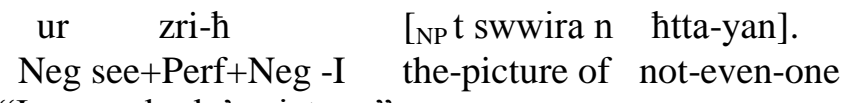

"I saw nobody's picture."

$$
\begin{array}{ccc}
\text { ur } & \text { i-mun } & { }_{\text {pp }} \mathrm{d} \text { htta-yan]. } \\
\text { Neg } & \text { he-leave+Perf } & \text { with not-even-one }
\end{array}
$$

"He did not leave with anyone."

In the same vein, like argument NPs, ' $h t t a+N P '$ can occur in a position higher than 'ur':

(5) a. Hmad (*ur) i-fti.

HamdNeghe-leave+Perf+Neg

"Hmad did not leave."

$$
\begin{array}{lrl}
\text { b. htta-yan } & \text { (*ur) } & \text { i-fti. } \\
\text { not-even-one } & \text { Neg } & \text { he-leave+Perf+Neg }
\end{array}
$$

"Noone left."

So far, distributional evidence has shown that N-words display the same distribution as any other argument NP. In these contexts, the N-words have no autonomous negative force and must co-occur with 'ur'. I take this fact to indicate that these elements enter into a licensing relation with the negative head 'ur'. The question that arises then concerns the structural configurations required for $\mathrm{N}$ word licensing operations. This will be the object of the following section.

\section{Structural configurations for $\mathrm{N}$-word licensing}

\subsection{Formal licensing}

In Chomsky's Minimalist Program (Chomsky 1995), formal licensing operations are defined as feature matching operations. In this approach, abstract morphological features associated with one type of element must be correctly paired with corresponding features on a second element. As elements with features that need checking will be base-generated structurally apart from their licensing or checking heads, the strict locality condition on feature-checking will trigger movement of the former to the latter. The positions involved in the feature 
matching operations are the specifier and the head positions of functional projections.

This feature matching approach to formal licensing offers an explanation for the Neg-N-word relation in Amazigh: N-words carry Neg-features, which require to be matched with corresponding features on the functional head $\mathrm{Neg}^{\circ}$. Consider (6):

(6) a. ur zri -h htta-yan.

Neg see+Perf+Neg-I not-even-one

"I did not see anyone."

b. htta-yan ur- $\mathrm{t}$ zri $-\hbar$.

not-even-one Neg-him see+Perf+Neg-I

"Noone did I see."

(6) gives rise to negative concord. Readings of negative concord will arise where there is some kind of direct association between an N-word and Neg (Haegeman and Zanuttini 1996: 118). The fact that this reading is available in (6) entails that a Neg-feature checking/licensing relation obtains between 'httayan' and 'ur' 2 .

At this point, one may ask the following question: What are the appropriate structural configurations required for the licensing of postverbal (6a) and preverbal (6b) N-words?

\subsection{Postverbal N-words}

Let us consider the data in (7) and (8), and see how postverbal N-words are licensed in Amazigh ${ }^{3}$ :

(7) a. uri-mmuddi htta-yan.

Neghe-travel+Perfnot-even-one

"No one traveled."

b.

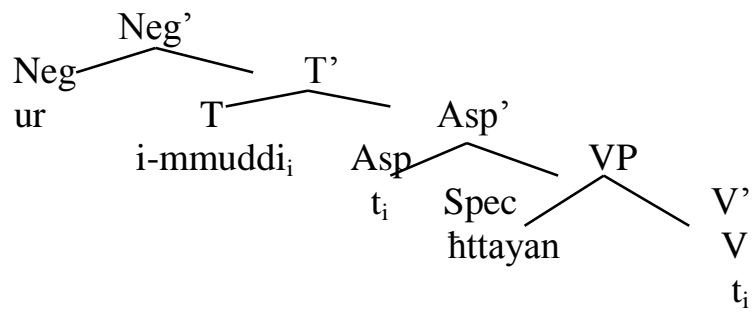


(8) a. ur zri $-\hbar$ htta-yan

Neg see+Perf+Neg-I not-even-one

"I did not see anyone."

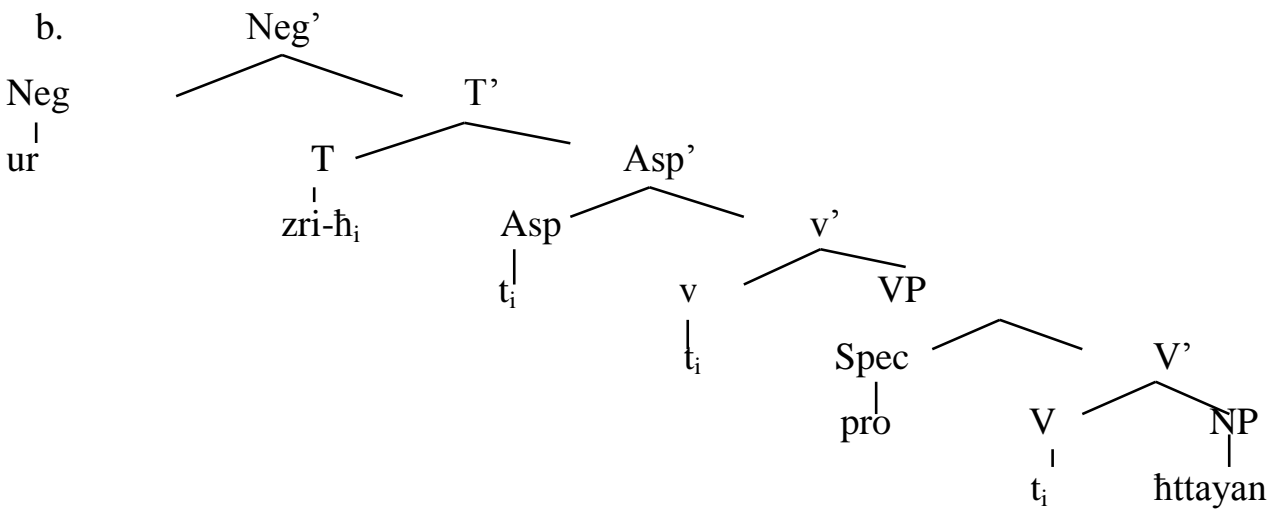

In (7), the $\mathrm{N}$-word is in $[\mathrm{Spec}, \mathrm{VP}]^{4}$. In that position, it is c-commanded by the head of NegP. Similarly, the N-word in (8) is in the object position within VP, where it is in the c-command domain of the Neg which licenses it. Thus, the strict locality condition on feature-checking requires that raising to [Spec, NegP] take place at LF. The evidence for a covert movement analysis is based on the observation that Neg-N-word dependencies are subject to locality constraints that usually apply to movement (Moritz and Valois 1994; Souâli 1996; Valois 1997; Souâli 2000). Citing Longobardi (1991), Moritz et al. (1994), for example, report that there is a parallel between rules operating on wh-syntactic movement and those responsible for scope assignments of N-words in Italian. This parallelism is attributed to the fact that $\mathrm{N}$-words undergo LF movement.

In what follows, I will show that licensing of N-words in Amazigh cannot be reduced to constraints that regulate wh-movement. I will also provide counterexamples to the covert movement of $\mathrm{N}$-words. Thus, the analysis will refute the strict locality condition on feature checking.

\subsubsection{Longobardi's correspondence hypothesis}

As reported in Moritz et al. (1994), Longobardi (1991) notes that the dependency between Neg and in-situ N-words in Italian exhibits properties of overt syntactic movement. He proposes to account for this by assuming that the scope of Neg must be reflected in the LF representation of a sentence, that is, by LF raising of the N-word to some sentence initial position (the Correspondence Hypothesis). The following properties are isolated by Longobardi. The Italian data is based on Moritz et al. (1994: 671-672), adapted from Longobardi (1991).

First, the distribution of N-words is sensitive to strong islands (i.e. it is subject to the Condition on Extraction Domains (CED)). The example in (9) is an instance of the Adjunct Condition. As indicated, the negative expression 
'nessuno' cannot move to its scope marker 'non' as this would involve moving out of an island:

(9) *Non fa il suo dovere [per aiutare nessuno].(Italian)

Neg he-does the his duty for to-help nobody

"He does not do his duty in order to help anyone".

Second, N-words display "connectedness effects" similar to those found in multiple wh-questions. In (10), the presence of the second N-word 'niente' voids the Adjunct Condition:

$$
\begin{aligned}
& \text { Non fa niente [per aiutare nessuno] } \\
& \text { Neg he-does nothing for to-help nobody } \\
& \text { "He doesn't do anything in order to help anyone." }
\end{aligned}
$$

Third, $\mathrm{N}$-words are unbounded. In (11), for example, the $\mathrm{N}$-word can have scope wider than the clause that dominates it in the overt syntax:

(11) Non credo che lui pensi che io desideri vedere nessuno. (Italian)

Neg I-believe that he thinks that I wish to-see nobody

"I do not believe that he thinks that I wish to see anyone."

The question now arises whether ' $h$ tta+NP' displays the same properties. Let us first look at the first property, namely CED effects.

One piece of evidence that ' $\hbar t t a+N P$ ' involves movement concerns the ECP, which requires non-pronominal empty categories to be properly governed (Souâli2000). Thus, if we assume, following Souâli, that N-words are raised at LF, leaving a trace in their extraction site, the ungrammaticality of (11b), as opposed to the grammaticality of (12a), will be accounted for in terms of ECP effects $^{5}$ :

(12) a. ur rri $-\hbar$ ad i-ftu htta-yan.

Neg hope+Perf+Neg-I that he-leave+A not-even-one

"I hope that noone will leave."

b.*ur rri - $\hbar$ ad htta-yan i-ftu.

Neg hope+Perf+Neg-I that not-even-one he-leave+A.

"I hope that noone will leave."

In (12a) 'ur' serves as a scope marker for the N-word in the embedded clause. In order to maintain matrix scope, the $\mathrm{N}$-word 'htta-yan' moves to adjoin to the matrix clause at LF.

$$
\begin{array}{lll}
{\left[\text { NegP } \hbar t t a-y_{i}\right.} & {[\text { ur rri }-\hbar} & {[\mathrm{cPad} i-f t u} \\
\text { not-even-one } & \text { Neg hope-I } & \text { that he-leave+A }
\end{array}
$$

(12b) is ungrammatical. The ungrammaticality of (12b) is analogous to that-trace effects in (14):

(14) a. *Who did you think that $t$ would arrive first?

b. *Whodid you think would arrive first?

(Haegeman 1995: 80)

In (14a) the extraction of 'who' results in a configuration where the subject trace fails to be properly governed. The ungrammaticality of (12b) is accounted for in similar terms if we adopt the hypothesis that 'htta-yan' undergoes LF movement. This movement would lead to the following representation:
$(15) *\left[_{\text {Neg }}\right.$ htta
- yan $_{\mathrm{i}} \quad[\mathrm{ur}$
rri-
$\hbar$ ad [ $\left.\left.\left.t_{i} \quad \mathrm{i}-f t u\right]\right]\right]$. 
not-even -oneNeghope+Perf+Neg-Ithat he-leave+A.

Another argument for the covert movement is provided by the fact that ' $\hbar t t a+N P '$, like 'nessuno', may not occur across strong islands, such as complex NPs and adjunct CPs, paralleling the fact that wh-extraction from such positions is not allowed:
(16)a. *ur zri
$-\hbar$
[argaz 1li
i- $\hbar m l-n$
htta-yan].
Neg see+Perf+Neg-I the-man who he-like+Perf not-even-one

"I did not see the man who likes anyone".

b. *manwa ${ }_{i}$ ad t-zri-t [argaz lli-st i-hml-n $\left.\mathrm{t}_{\mathrm{i}}\right]$ ?

Who that you-see+Perf the man who-her he-like+Perf

"Who did you see the man who likes?"

(17)a. *ur i-fti

s 1-xdmt[cpbaš ad i-mmaggar htta-yan.]

Neg he-go+Perf+Neg to the-work so that that he-meet+A not-even-one

" "He did not go to work to meet anyone.",
b. ${ }^{*}$ manwa $_{\mathrm{i}} \quad \mathrm{t}$-ffe $\gamma-\mathrm{t} \quad\left[\mathrm{cp} \mathrm{qbl}\right.$ ad -t $\mathrm{t}$-maggar-t $\left.\mathrm{t}_{\mathrm{i}}\right]$ ?
who you-leave+Perf before that-him you-meet+A
"Who did you leave before you met?',

The examples in (12-17) show that movement in the syntax and movement at LF obey the same locality conditions. This may be taken to argue for a movement analysis whereby N-words must move at LF to a position which is the specifier of a negative head. Moreover, this may also suggest that such movement is possible as long as the N-word is not within an island which blocks extraction, as indeed is proposed in Longobardi for Italian. If such locality facts are interpreted as indication that postverbal $\mathrm{N}$-words do undergo movement, then seen from a Minimalist perspective, this can be explained in terms of raising to satisfy feature-checking requirement.

In terms of the MP, covert $\mathrm{N}$-word movement in Amazigh may be explained by supposing that $\mathrm{Neg}^{\circ}$ carries weak Neg-features, and hence requires post Spell-Out checking. Overt N-word movement in (18) is thus barred by the Procrastinate Principle:

(18) $* \hbar t t a \quad-y_{i} \quad$ ur zri $\quad-\hbar t_{i}$.
Not even -one Neg see+Perf+Neg-I

Sadiqi and Ennaji (1999) provide a similar account for postverbal N-words in Standard Arabic. They argue that overt movement is barred by the Procrastinate Principle because the features of Neg are weak. Therefore, these N-words must remain in situ until LF. At this level, they can satisfy the requirement of feature checking. This is illustrated in (19):

lam ashtari ayya kita:bin.
Neg I-buy+perf any book
"I didn't buy any book".

So far I have established that, like that of 'nessuno', the distribution of ' $h$ tta+NP' seems subject to the CED. In the next subsection, I look at counterexamples to the covert movement analysis. 


\subsubsection{Counterexamples to the covert movement analysis}

Although sensitivity to the CED and the ECP would appear to be a fair indication that ' $\hbar t t a+N P$ ' undergoes LF movement, this conclusion is not necessarily correct. There are several reasons for this.

First, although $\mathrm{N}$-words display a property shared by wh-phrases, namely sensitivity to strong islands, this cannot immediately be taken as an indication that LF movement is involved. Rather, it can be claimed that sensitivity to islands could equally be expressed in terms of a condition which constrains the formation of a chain between Neg and the N-word, much along the lines of Cinque's (1990) analysis of Clitic Left Dislocation in Italian (cf. Moritz et al. 1994; Simpson 1996).The condition can be stated as follows:

(20) $*[$ ur...[a...ћtta+NP...]...]

Where $\alpha$ is an island.

Second, the ungrammaticality of examples like (12b), repeated here as (21), cannot be explained in terms of ECP effects. Rather, $(12 b)$ is excluded by the Procrastinate Principle. Since Tense in Amazigh carries a weak [D] feature, the subject must stay inside VP until after Spell-Out, as can be seen in (12a), repeated here as (22):

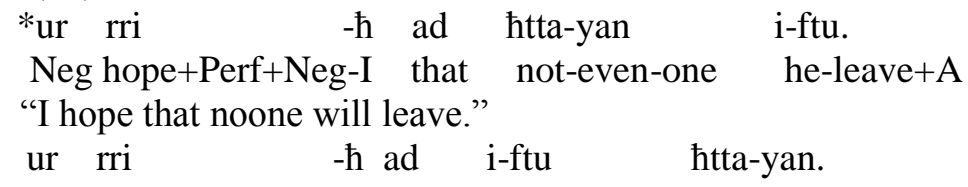

Neg hope+Perf+Neg-I that he-leave+A not-even-one

"I hope that noone will leave."

Third, an N-word can be the complement of a preposition in a PP complement, while a wh-trace cannot. This is shown by the contrast in (23) and (24):

$$
\begin{aligned}
& \text { ur i-sawl } \left.\quad \begin{array}{lll}
\mathrm{pp} & \mathrm{s} & \hbar \text { tta-yan}
\end{array}\right] \\
& \text { Neg he-speak+Perf to not-even-one } \\
& \text { "He did not speak to anyone" } \\
& \text { *manwa ad i- sawl } \\
& \text { who that he-speak+A } \\
& \text { "Who did he speak to?" }
\end{aligned}
$$

Finally, N-words are not allowed in contexts from which wh-phrases can easily be extracted (Moritz et al. 1994; Simpson 1996;Benmamoun 1997). For example, an $\mathrm{N}$-word within an embedded tensed clause cannot be licensed by $\mathrm{Neg}$ in the higher clause, as in (25):

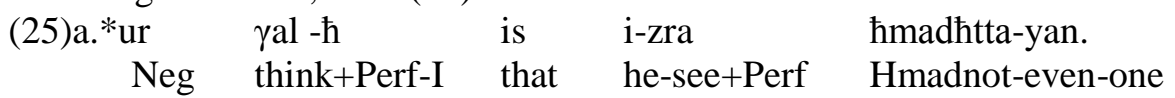

"I don't think that Hmad saw anyone."

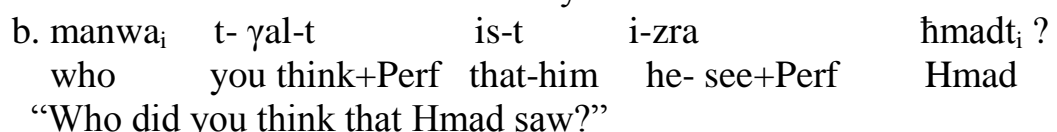

As tensed CPs do not constitute islands for wh-movement in Amazigh, there would seem to be no reason why LF raising should be blocked in sentences like 
(25a) above. One way out is to assume that a tensed CP constitutes a barrier for LF movement but not for pre-Spell-Out movement (Zanuttini1991). This assumption, however, does not accord with Minimalist views that the application of constraints on movement should be uniform throughout a derivation and may not vary depending on whether movement occurs prior to or after Spell-Out.

The evidence presented so far indicates that licensing of $\mathrm{N}$-words cannot be totally reduced to constraints that regulate wh-movement. This in turn weakens the assumption that licensing of $\mathrm{N}$-words can occur at LF where such movement would take place. Therefore, it is reasonable to conclude that in well-formed cases like (7) and (8) above, N-words may not undergo any raising, but due to the position they occupy, i.e. base-generated in the c-command of Neg, their features will be checked successfully. ${ }^{6}$

\subsection{Pre-verbal $\mathbf{N}$-words}

Consider the following example:

(26)

htta-yanuri-fti.

not-even-oneNeghe-leave+Perf+Neg

"No one left."

Following Omari (2001), I assume that preverbal NPs in Amazigh are inserted in their surface position by Merge. In that position, they enter in a non-local agreement relation with 'pro' in the subject position in [Spec, VP]. Given this assumption, we could suggest that the preverbal $\mathrm{N}$-word in (26) is base generated in [Spec, NegP] where it is in Spec-head agreement relation with the head Neg, in conformity with the strict locality condition on feature checking (Chomsky1992/95). If the $\mathrm{N}$-word is in [Spec, NegP], then an adjacency requirement must be satisfied. The special status of specifiers is explained by a Minimality requirement on licensing: Nothing may intervene between two elements in a licensing relation.

However, this minimality requirement is called into question by the existence of structures like (27):

(27) htta-yanbeda uri-fti.

not-even-one at least Neghe-leave+Perf+Neg

"At least, no one left."

The adverb 'beda' in (27) intervenes between the N-word 'httayan' and the head 'ur', in apparent violation of the minimality requirement on licensing. One way out is to suggest that the adverb is adjoined to a functional projection above NegP, namely FocP. As such, the word order in (27) is derived from moving ' $\hbar$ ttayan' from [Spec, NegP] to [Spec, FocP].Such raising can be assumed to check focuslike features generated on the N-word:

(28)

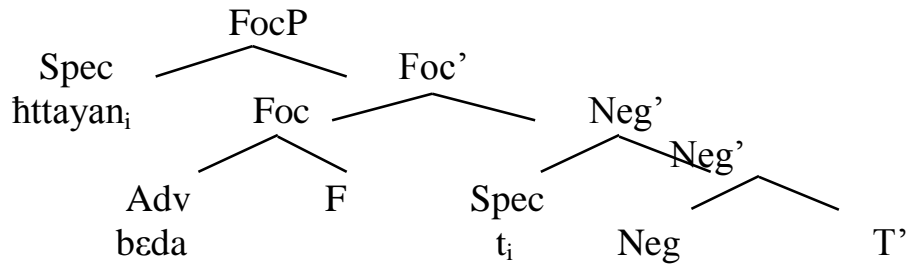


ur

There are, however, structures such as (29) that argue against a movement analysis of the $\mathrm{N}$-word. The locality constraints on movement are not applicable to the relation between the NP 'htta-yan' and its associated gap in [Spec, NegP]:

(29) a. htta-yan ${ }_{i}$ [IPSsen- $\hbar$ [CP is [NegP $t_{i} u r$ i-fti]]].

not-even-one know+Perf-I that Neg he-leave+Perf+Neg

"I know that noone left."

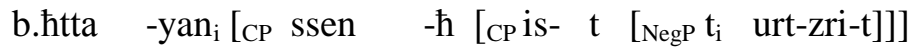

$$
\begin{aligned}
& \text { not-even- one know +Perf-I that-him Neg you-see+Perf+Neg } \\
& \text { "I know that you saw no one." }
\end{aligned}
$$

(29) cannot have arisen from movement of the N-word 'htta-yan' within the lower embedded clause to the position it occupies in the example above. Such an operation would have extracted 'httayan' across a number of intermediate positions [CP, IP] in a single step, in violation of the Shortest Move Principle. Thus, the derived structure would have been wrongly predicted to be ill-formed. A plausible hypothesis is to claim that the N-word 'httayan' is inserted in [Spec, TopP] by Merge. The preverbal $\mathrm{N}$-words in (26) can thus be characterized syntactically as being in the configuration diagrammed in (30) with an empty head:

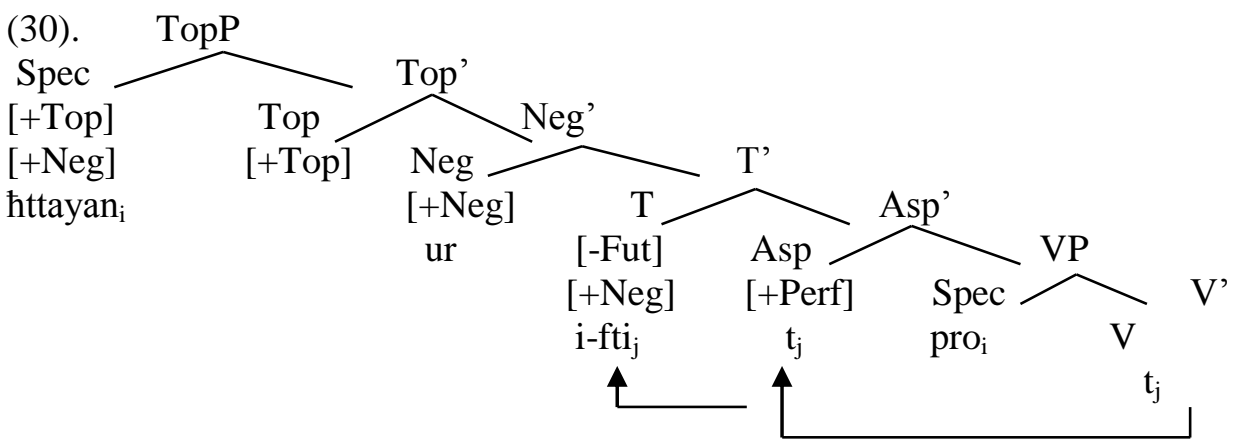

' $\mathrm{Httayan}_{\mathrm{i}}$ 'in (30) is co indexed with ' $\mathrm{pro}_{\mathrm{i}}$ ' in the canonical subject position [Spec,VP].The nominative case is checked by attraction of the case feature from ' $\mathrm{pro}_{\mathrm{i}}{ }^{\prime}$ to T. In this case, 'pro'allows the case checking process to proceed in the relevant inflectional domain, thus freeing the $\mathrm{N}$-word from the restrictions imposed by the MLC. Even though the preverbal N-word 'htta-yan' in (26-29) is not in the c-command domain of Neg, its Neg-features are properly licensed by being co indexed with 'pro'which is c-commanded by $\mathrm{Neg}^{\circ}$, as in (26) and (29). This entails that it is not the $\mathrm{PF} / \mathrm{Spell}-\mathrm{Out}$ point of the preverbal N-word which is relevant for licensing but other position to which the $\mathrm{N}$-word is coindexed (Benmamoun, 1997; Omari2001).

\section{Further evidence from Moroccan Arabic}

I turn to Moroccan Arabic (MA) and show that evidence similar to that considered in Amazigh can also be found in other languages ${ }^{7}$. A similar analysis will thus be 
entertained, one which argues for a different view of feature checking/licensing from that proposed in Chomsky 1992/95. The relevant data and analysis are based on Benmamoun (1997).

Given the assumption that NegP in $\mathrm{MA}$ is also generated above TP (Souâli2000), N-words may occur in subject (33) as well as in object (34) positions:

a.

$$
\begin{array}{ll}
\text { ma- mša } & \text { ћtta-waћed. } \\
\text { Neg- leave+Perf-he } & \text { not-even-one }
\end{array}
$$

"No one left."

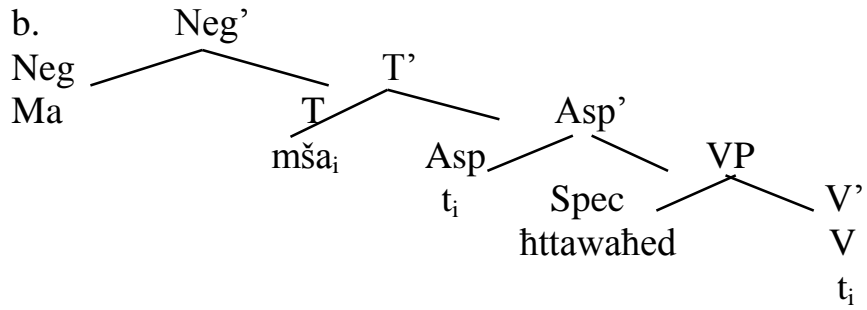

(32) a. ma šeft ћtta-waћed.

Neg see+Perf- I not-even -one

"I did not see anyone".

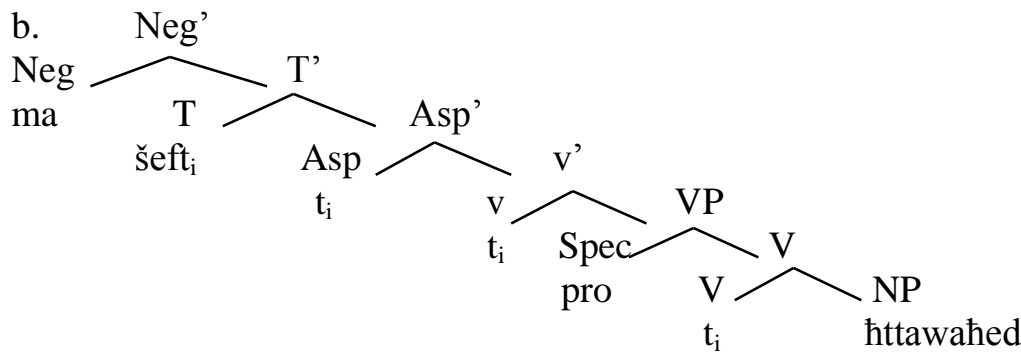

If we were to adopt the position that $\mathrm{N}$-words in situ at $\mathrm{PF}$ need to undergo raising to Neg at LF, we might suggest that in cases like (31) and (32), the Nwords in postverbal positions undergo covert movement to [Spec, NegP]. However, within a covert movement analysis of $\mathrm{N}$-words, the following facts are problematic.

The main problem is seen in constructions that display reconstruction effects. As shown in Benmamoun (1997), fronted PPs in Arabic undergo reconstruction effects. Data in (33) and (34) illustrate this point:

(33) kanu lə-wlad tayləebu mea bəedhum.

were-they the-children play-they with each-other

"The children were playing with each other."
mea bəedhum kanu
lo-wlad
tayləebu.
With each-other were-they the-children play-they 
"The children were playing with each other."

(Benmamoun 1997: 280)

(33) and (34) are identical except that the PP containing the anaphor is in situ in (33) and fronted in (34). The anaphor within the PP in (33) is bound by the ccommanding subject 'lowlad'. This is consistent with binding theory which requires that an anaphor be c-commanded by its antecedent. The relevant bound reading in (34) follows from the assumption that the PP reconstructs to its original position at LF. Consequently, the binding requirement on the anaphor takes place at LF, where the subject NP c-commands the anaphor 'bəedhum'.

If the licensing of $\mathrm{N}$-words can take place at LF, we predict that these elements can be fronted inside PPs. At LF, they must reconstruct to the Spec of $\mathrm{NegP}$ for licensing purposes. However, this prediction is not borne out. A fronted PP cannot contain an N-word, as the contrast between (35) and (36) clearly shows:

$$
\begin{aligned}
& \text { ma -kanu lə-wlad tayləebu mea ћətta-waћəd. } \\
& \text { Neg-were-they the-children play-they with even -one } \\
& \text { "The children were not playing with anyone." } \\
& \text { *mea ћətta-waћəd ma-kanu lə-wlad tayləebu. } \\
& \text { with even-one Neg-were-they the-children play-they }
\end{aligned}
$$

(Benmamoun 1997: 280)

Since I have shown that fronted PPs may display reconstruction effects, sentence (36) should be grammatical if licensing of N-words can take place at LF. After reconstruction, the sentence (36) is identical to (35). Thus, if the N-word is licensed in (35), it should equally be licensed at LF by reconstruction to the Spec of NegP.

Second, as with Amazigh, if the licensing of N-words in-situ were to reduce to covert movement to the [Spec, NegP], there would seem to be no reason why $\mathrm{N}$-words should not be able to occur in embedded tensed CPs as in (37). Movement to the matrix clause should be possible given that tensed CPs do not constitute islands for overt instances of wh- extraction (38):

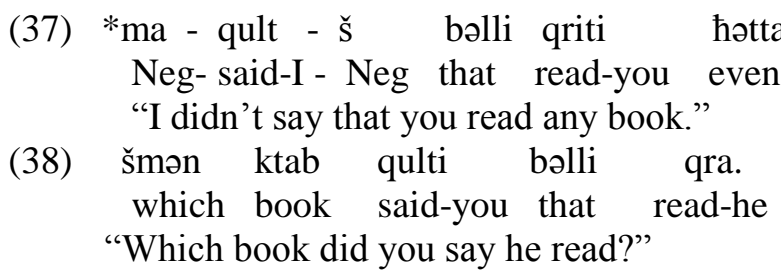

(Benmamoun 1997: 284)

The evidence presented above strongly indicates that LF movement of $\mathrm{N}$ words does not take place in MA. Therefore, as with Amazigh, postverbal Nwords in examples such as (31) and (32) are licensed in the c-command domain of $\mathrm{Neg}$, and do not need to undergo movement to any other position for Neg-feature checking.

A similar account can be provided for preverbal $\mathrm{N}$-words in MA. Presumably, these $\mathrm{N}$-words are base-generated in their surface position, which is 
higher than NegP (Omari 2001).For these elements, it seems that being co indexed with 'pro' which is in the c-command domain of Neg is sufficient for licensing:

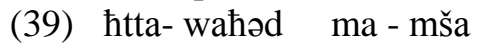
not- even-one Neg -leave+Perf-he

"Noone left."

\section{Conclusion}

In this paper, I offered an analysis for N-word Licensing in Amazigh. Most specifically, I examined configurations that permit $\mathrm{N}$-word licensing and the level of representation where licensing must take place. I showed that the relevant facts require a certain qualification of Chomsky's (1995) system. In the suggested analysis, Neg-features present on N-words are checked overtly. On the basis of some evidence from Amazigh and MA, I indicated that $\mathrm{N}$-words are checked prior to Spell-Out in the position they occupy, i.e. base generated in the c-command domain of Neg. As such, feature checking is not universally restricted to occurring within Spec-head or head adjoined positions, but rather may also be satisfied between elements occurring within some larger domain.

Naima Omari (PhD)

Ibn Zohr University, Morocco

Email: naimaomari2004@yahoo.com 


\section{Endnotes}

1. The term 'N-words' has been employed by various linguists to refer to certain elements in various languages that co-occur with and are licensed by Neg (Linebarger 1987; Zanuttini 1991; Simpson 1996; Benmamoun1997; Zanuttini1997; Omari 2001;Ouali 2011, among others).

2. When two (or more) negative elements are present in a given domain, two different situations may arise: (a) the two negative elements may cancel each other out (i); or (b) the two negative elements may constitute, together, one instance of negation (ii). The former is referred to as double negation, whereas the second case is called negative concord (Haegeman1995).

(i) I didn't see nothing.

(ii) I didn't see anything.

3. In 'pre-Minimalist' accounts, N-words are licensed by Neg under c-command (Laka 1990). In English, for example, there is a subject/object asymmetry with respect to $\mathrm{N}$ word licensing, in that sentence negation does not license subject $\mathrm{N}$-words, but it licenses object N-words:

(i) *Anybody didn't come.

(ii) Mary didn't see anything.

(Laka 1990: 35)

(i) is ruled out because the $\mathrm{N}$-word is not licensed by $\mathrm{Neg}^{\circ}$, which does not c-command it. The reverse situation holds in (ii), which is well-formed. In a configuration like the one adopted here for Amazigh, Neg c-commands all arguments in TP; this correctly predicts that Amazigh allows $\mathrm{N}$-words in subject as well as in object positions, as illustrated in (6) and (7). (See Omari 2011 for a detailed analysis of Amazigh clause structure).

4. My analysis for languages which have VS order, like Amazigh, is that the verb is raised out of the VP to T before Spell-Out, but that the subject stays inside VP until after SpellOut (Omari 2001). VSO languages, therefore, differ from SVO languages, such as French, in that the latter must also move the subject before Spell-Out. In both types of languages, the object stays inside VP until LF. Following Boukhris (1998), I assume that in Amazigh the objective case-feature carried by the object is checked by percolation of the [+Acc] feature to the functional head $\mathrm{v}$, which is projected only in transitive sentences. As pointed out by Boukhris, the functional head $\mathrm{v}$ in Amazigh carries weak [+D] feature which is checked at LF and a strong [+V] feature which is checked overtly.

5. Souâli (2000) assumes that Spec-head relation holds between Neg and N-words. He argues that the $\mathrm{N}$-word must move from its base position to the specifier of this functional category at LF for licensing purposes. The main argument for $\mathrm{N}$-word raising at LF is provided by ECP facts, as in (i):

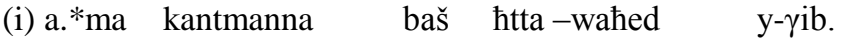
Neg Imperf-hope+I that even -one he-be absent
"I hope that nobody will be absent."

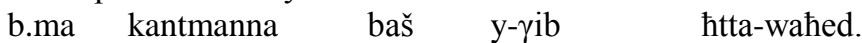
Neg Imperf-hope+I that he-be absent even -one

Assuming that $\mathrm{N}$-words are raised at $\mathrm{LF}$, leaving a trace in their extraction site, the ungrammaticality of (ia), as opposed to the grammaticality of (ib), is accounted for in terms of ECP. In (ia), the ECP is violated at LF, since the trace of the N-word is left in a 
non-properly governed position. By contrast, in (ib), the principle is not violated, given that the trace is properly governed by $\mathrm{V}$.

6. Haegeman (1995) accounts for the licensing of postverbal N-words by adopting a representational approach based on Aoun and Li (1993). She proposes that in languages without apparent $\mathrm{N}$-word movement, the Neg-Criterion is satisfied by a non-overt expletive operator in $[\mathrm{Spec}, \mathrm{NegP}]$ which enters into a chain with the contentive negative operator. (ia) would have the partial representation in (ib):
(i) a. ur i-mmuddi
htta-yan.

Neg he-travel+perf+Neg not-even-one

"No one left."

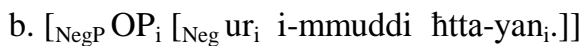

In (ib) the N-word 'httayan' satisfies the Neg-Criterion by the formation of a representational chain with the base-generated non-overt expletive-operator $\mathrm{OP}_{i}$ in $[\mathrm{Spec}$, $\mathrm{NegP}$. This non-overt operator, being a non-overt category, has to be identified by association with overt material. The non-overt operator in [Spec, NegP] is a scope marker for the N-word 'htta-yan' and the two are co indexed. It is not possible to suggest that an empty operator is co indexed with the N-word 'httayan' in (i); if this were to be so, then it should be possible for such an empty operator to enter into a chain with $\mathrm{N}$-words occurring in embedded tensed CPs, and examples like (iii) would incorrectly be predicted to be well-formed:
(iii) a *ur yal $\hbar \quad[$ cP is ifta $\quad$ htta-yan. $]$
Neg think+perf-I that he-leave+perf not-even-one
"I don't think noone left."
b. [NegP OP HA ur $_{i}$ yal- $\hbar$ [CP is ifta $\left.\left.\left.\hbar t t a-y a n_{i}\right]\right]\right]$

7. For detailed analysis of N-words in Moroccan Arabic, see Chaker and Caubet 1996; Benmamoun 1997,2000. 


\section{References}

Aoun, Joseph, and Yen-hui Audrey Li. (1993). Syntax of Scope. Cambridge: Mass.: MIT Press.

Benmamoun, Elabbas. (1997). 'Licensing of negative polarity items in Moroccan Arabic'. Natural Language and Linguistic Theory, 15: 263-287.

Benmamoun, Elabbas.(2000). The Feature Structure of Functional Categories: A Comparative Study of Arabic Dialects.Oxford University Press.

Chaker, Salem. and Dominique Caubet. (1996). (eds.). La Négation en Berbère et en Arabe Maghrébin. L'Harmattan.

Chomsky, Noam. (1992). 'A minimalist program for linguistic theory'. MIT Occasional Papers in Linguistics, 1 .

Chomsky, Noam. (1995).The Minimalist Program. Cambridge, Mass.: MIT Press.

Cinque, Gulgielmo. (1990). Types of A'-Dependencies. Cambridge, Mass.: MIT Press.

Haegeman, Liliane. (1995). The Syntax of Negation. Cambridge: Cambridge University Press.

Haegeman, Liliane and RaffaellaZanuttini. (1996). 'Negative concord in west Flemish'. In AndrianaBelletti, and Luigi Rizzi (eds.), Parameters and Functional Heads, 117-179. Oxford University Press.

Laka, Itziar. (1990). Negation in syntax: on the nature of functional categories and projections. Ph. D. Thesis, MIT.

Linebarger, Marcia C. (1987). 'Negative polarity items and grammatical representation'. Linguistic and Philosophy, 10: 325-387.

Moritz, Luc. and Daniel Valois. (1994). 'Pied Piping and Specifier Head Agreement'. Linguistic Inquiry, 25: 667-707.

Omari, Naima. (2001). The syntax of negation in Tashelhit: a comparative approach. Ph. D. Thesis, Mohamed V University, Rabat, Morocco.

Omari, Naima. (2011).'Some aspects of Amazigh clause structure'. LINCOM Studies in Afroasian Linguistics, 32.

Ouali, Hamid. (2011).Agreement, Pronominal Clitics and Negation in Tamazight Berber: A Unified Analysis. Continuum Studies in Theoritical Linguistics.

Sadiqi, Fatima and MohaEnnaji. (1999). 'Negation, tense and the licensing of $\mathrm{N}$-words in Standard Arabic'. Languages and Linguistics, 4: 19-43.

Simpson, Andrew. (1996). 'N-word licensing in French, Italian, and West Flemish'.SOAS Working Papers in Linguistics and Phonetics, 16: 298-321.

Souâli, El Hassan. (1996). 'Sentential negation and parametric variation'.Linguistique Comparée et Langue au Maroc, 51: 129-138.

Souâli, El Hassan. (2000). 'The Negparameter and the Negcriterion'. Variation Linguistique: Des faits aux Théories, 167- 176.Fez: Universidad de Fez. 
Valois, Daniel. (1997). 'Négation, interrogation, et accord specificieur-tête'. Revue Québécoise de Linguistique, 25: 99-120.

Zanuttini, Raffaella. (1991). Syntactic properties of sentential negation. A comparative study of Romance Languages. Ph.D. Dissertation. University of Pennsylvania.

Zanuttini, Raffaella. (1997). Negation and Clause Structure: A Comparative Study of Romance Languages. Oxford, Oxford University Press. 